\title{
Predictive validity of the gait scale in the Performance Oriented Mobility Assessment for stroke survivors: a retrospective cohort study
}

\author{
Seungheon $\mathrm{An}^{\mathrm{a}}$, Youngju Jee ${ }^{\mathrm{b}}$, Donggeon Lee ${ }^{c}$, Sunhae Song ${ }^{c}$, Gyuchang Lee ${ }^{d}$ \\ ${ }^{a}$ Department of Physical Therapy, National Rehabilitation Center, Seoul, Republic of Korea \\ ${ }^{b}$ Department of Nurse, Kyungnam University, Changwon, Republic of Korea \\ 'Department of Physical Therapy, Graduate school of Kyungnam University, Changwon, Republic of Korea \\ ${ }^{\mathrm{d} D e p a r t m e n t}$ of Physical Therapy, College of Natural Sciences, Kyungnam University, Changwon, Republic of Korea
}

Objective: The present study was to investigate the discrimination capacity of the Performance Oriented Mobility Assessment-Gait Scale (POMA-GS), for predicting falls in stroke survivors.

Design: Retrospective cohort study.

Methods: Data including the characteristics and number of falls of 52 chronic stroke patients from a rehabilitation center were collected. The number of falls each subject had experienced in the previous year were investigated through interviews. The subjects were divided into two groups depending on the number of falls: if falls occurred twice or more on the basis of the time of study after stroke, they were defined as the falls group and if there was no fall experience or one fall, they were defined as the non-falls group. The subjects were examined with the POMA-GS, and physical functions were examined using by the One Leg Stand Test (OLST), Sit to Stand Test (SST), 10-m Walk Test, Lower Extremity in Fugl-Meyer assessment (FM-LE), and Trunk Impairment Scale (TIS). The validity of POMA-GS for falls prediction was analyzed.

Results: In the POMA-GS, which predicts falls in stroke survivors, the cut-off value was 8.5 (sensitivity $72 \%$; specificity $65 \%$ ) and the area under the curve was 0.75 (95\% confidence interval: $0.60-0.90, p<0.007)$. There was a significant difference in the OLST, SST, FM-LE, and TIS between the subjects with POMA-GS $>8.5$ and the subjects with POMA-GS $\leq 8.5$.

Conclusions: The POMA-GS could be a useful tool in predicting falls in stroke survivors, as its discrimination capacity and predictive validity is proven satisfactory.

Key Words: Accidental falls, Stroke, Tinetti Performance Oriented Mobility Assessment-Gait Scale

\section{Introduction}

Gait is a complex motor skill that is based on the balance ability and coordinated movement of the lower extremity and thus is adjusted by the interaction between the neurologic and musculoskeletal systems that adapts rapidly to the surrounding environments and the changed purposes [1]. Patients with neurological problem such as stroke show muscle weakness, abnormal muscle tone, sensory dysfunc- tion, asymmetrical gait pattern, slow gait speed, reduced balance ability, and impaired postural control [2]. In general, if the gait speed of stroke patients is $<0.6 \mathrm{~m} / \mathrm{s}$, the spatiotemporal parameters of gait are likely to be asymmetrical and, in particular, have significant correlation with the symmetry of temporal parameters of gait and gait speed $(\mathrm{r}=$ -0.58) [3]. Since the symmetry of temporal parameters of gait were relevant to the function of the foot and lower extremity $(r=-0.63$ to -0.64$)$ in the Chedoke-McMaster Stroke

Received: 7 January, 2016 Revised: 5 March, 2016 Accepted: 7 March, 2016

Corresponding author: Gyuchang Lee

Department of Physical Therapy, College of Natural Sciences, Kyungnam University, 7 Kyungnamdaehak-ro, Masanhappo-gu, Changwon 51767, Republic of Korea Tel: 82-55-249-2739 Fax: 82-505-999-2173 E-mail: leegc76@kyungnam.ac.kr

(c) This is an Open-Access article distributed under the terms of the Creative Commons Attribution Non-Commercial License (http://creativecommons.org/licens es/by-nc/4.0) which permits unrestricted non-commercial use, distribution, and reproduction in any medium, provided the original work is properly cited.

Copyright $@ 2016$ Korean Academy of Physical Therapy Rehabilitation Science 
Assessment, the body leaned more heavily toward the nonaffected side in the lower extremity when the asymmetry of gait increased [3]. Moreover, balance ability affected the stroke patients with slow gait speeds ( $\leq 0.48 \mathrm{~m} / \mathrm{s})$, and cardiopulmonary function affected the patients with fast gait speeds $(>0.48 \mathrm{~m} / \mathrm{s})$ [4]. Thus, if the gait speed is $<0.56$ $\mathrm{m} / \mathrm{s}$, the risk of repeated falls increase [5]. Because the slow gait speed that occurs after stroke decreases balance ability and increases gait asymmetry, safe movement is difficult and more fall risks are exposed. Therefore, it is important to prevent the falls that may occur while stroke patients are walking, and it is necessary to predict the risk of falls with an appropriate evaluation. However, since all stroke patients have different gait abilities and various factors that impact falls, it is difficult to evaluate these patients with piecemeal solutions.

The Timed Up and Go (TUG) test, 10-m Walk Test (10WT), 6-minutes walk test (6WT), and Functional Gait Assessment (FGA) have been used to measure the spatiotemporal elements of gait when a patient moves in the direction that the inspector requests [6]. The TUG is an examination tool for measuring only the time consumed by a relatively simple task including change of direction by $180^{\circ}$ twice. Thus, it cannot evaluate balance ability in the various contexts required in everyday activities, and its identification of fall-related problems is very limited [7]. The 6WT has a floor effect for patients with slow gait speeds and is influenced by cardiopulmonary endurance rather than balance ability [4]. In addition, the Dynamic Gait Index (DGI) [8], which consists of an ordinal scale, and the FGA are the examination tools for dynamic balance to determine if it is possible to perform other tasks during gait and focus on evaluating postural control and mobility [9]. In particular, the examination tools may have limitations in that they have difficulty predicting falls in stroke patients.

The Performance-Oriented Mobility Assessment (POMA) determines the risk of falls in the elderly and measures locomotor ability. In particular, the gait scale in the POMA is simple to use, and it takes about 5 minutes to evaluate gait patterns such as spatiotemporal elements of gait in stroke patients, gait asymmetry, and step continuity and can be used with walking aids [10]. In addition, it includes fall-related movements such as hesitation when starting to walk [11], step length in the left and right side, foot clearance [12], postural sway [13], and walking stance [14]. It also includes balance-related elements such as weight bearing into the affected side and non-affected side, control of base of support and trunk stability, and path deviation [10,15]. Previous studies reported that the gait scale in the POMA had a high reliability and construct validity in stroke patients $[15,16]$, evaluated the postural stability using the center of pressure and center of mass [17], and investigated the predictability of falls using the total score from the balance and gait scale [18], However, no studies on the gait scale in the POMA have been conducted to evaluate the such as falls discrimination and predictive validity of gait scale has been conducted.

Therefore, the purpose of this study was to identify the discrimination capacity of the predictability of falls in the gait scale of the POMA in chronic stroke survivors, to analyze the relevance of physical functions with falls, and to verify the clinical usability.

\section{Methods}

\section{Subjects}

Sixty-nine stroke patients in a rehabilitation center were recruited through bulletin board advertising, and the subjects who met the following criteria were screened; individuals who experienced a stroke at least six months ago, individuals who could walk $>10 \mathrm{~m}$ without any assistance, individuals who did not have lower motor neuron disease in the lower extremity or musculoskeletal disease, and individuals with Mini-Mental State Examination scores $>24$. Subjects who had unadjusted diabetes or that affected gait were excluded. Of the recruited 69 stroke patients, 9 who did not meet the inclusion criteria were excluded. Eight patients who did not participate in the examination during the study period or were discharged from the hospital were excluded. Finally, the data of 52 subjects were collected and analyzed. The characteristics of the subjects who participated in this study are shown in Table 1. The purpose and procedure of this study were explained to all of the subjects who participated, and the subjects signed informed consent forms.

\section{Study design and procedure}

This was a retrospective cohort study. For data collection, the number of falls for the last year and general medical characteristics of the subjects (gender, age, diagnosis, affected side, disease duration, and use of walk aids) was recorded. General medical characteristics of the subjects were collected from the medical records. A research assistant investigated the number of falls each subject had experienced in the previous year through interviews with the pa- 
Table 1. Characteristics of subjects depending on falls experience $(\mathrm{N}=52)$

\begin{tabular}{lcccrr}
\hline \multicolumn{1}{c}{ Variable } & Total & Non-fallers (n=18) & \multicolumn{1}{c}{ Fallers (n=34) } & $\mathrm{X}^{2} / \mathrm{t}$ & $p$ \\
\hline Gender (male/female) & $35 / 17$ & $11 / 7$ & $24 / 10$ & 0.480 & 0.544 \\
Age (y) & $61.92(15.56)$ & $60.00(13.11)$ & $62.94(16.81)$ & -0.645 & 0.522 \\
Etiology (infarction/hemorrhage) & $36 / 16$ & $14 / 4$ & $22 / 12$ & 0.944 & 0.529 \\
Affected side (left/right) & $25 / 27$ & $7 / 11$ & $18 / 16$ & 0.931 & 0.392 \\
Stroke duration (mo) & $10.39(2.55)$ & $10.00(2.04)$ & $10.45(2.92)$ & 0.704 & 0.485 \\
Walking aids type (I/O/F) & $24 / 13 / 15$ & $13 / 2 / 3$ & $11 / 10 / 13$ & 7.820 & $0.02^{*}$ \\
POMA-GS (score) & $16.88(4.63)$ & $9.89(1.78)$ & $8.18(1.71)$ & 3.345 & $0.002^{* *}$ \\
OLST of affected side (s) & $3.09(3.12)$ & $4.38(4.18)$ & $2.40(2.15)$ & 2.269 & $0.028^{*}$ \\
OLST of non-affected side & $8.29(6.38)$ & $12.94(8.39)$ & $5.83(2.93)$ & 3.488 & $0.002^{* *}$ \\
SST (s) & $16.43(7.35)$ & $10.12(5.19)$ & $19.77(6.04)$ & -5.746 & $0.002^{* * *}$ \\
10WT (m/s) & $0.72(0.34)$ & $0.89(0.30)$ & $0.62(0.33)$ & 2.825 & $0.007^{* *}$ \\
FM-LE (score) & $22.13(7.22)$ & $26.39(6.49)$ & $19.88(6.61)$ & 3.417 & $0.002^{* *}$ \\
TIS (score) & $16.88(4.63)$ & $9.89(1.78)$ & $8.18(1.71)$ & 3.309 & $0.002^{* *}$ \\
\hline
\end{tabular}

Values are presented as number only or mean (SD).

I: Independent, O: one-point cane, F: four-point cane, POMA-GS: Performance-Oriented Mobility Assessment-Gait Scale, OLST: One Leg Stand Test, SST: Sit to Stand test, 10WT: 10-m Walk Test, FM-LE: Lower Extremity in Fugl-Myer assessment, TIS: Trunk Impairment Scale.

Significant differences among three groups were presented as ${ }^{*} p<0.05,{ }^{* *} p<0.01,{ }^{* * *} p<0.001$.

tient or family members. The subjects were divided into two groups depending on the number of falls: if falls occurred twice or more on the basis of the time of study after stroke, they were defined as the falls group and if there was no fall experience or one fall (because falls may be caused by overwhelming external force), they were defined as the non-falls group [19]. The criterion for falls applied in this study was the unintended change in posture not caused by epilepsy or seizure or by momentary or overwhelming external forces. Thus, a fall was defined as the unexpected events during which an individual might fall on the ground or an object [20]. After investigating the general characteristics and fall experiences, the subjects' balance was examined by using the gait subscale of the POMA in order to investigate the subscale's discrimination capacity and predictive validity. The examine physical functions, the One Leg Stand Test (OLST) of the affected side and the non-affected side, Sit to Stand Test (SST), 10WT, lower extremity in Fugl-Meyer assessment (FM-LE), and Trunk Impairment Scale (TIS) were performed. All examinations were conducted by two therapists. The examiners sufficiently understood the examination tools and read protocols and guidelines to minimize confounding variables. The subjects were allowed to rest for 2-5 minutes after each examination following a verbal or physical demonstration to help the subjects understand the next examination. All examinations, except for the gait subscale of the POMA, were performed over two days in the fol- lowing sequence: OLST, SST, 10WT, FM-LE, and TIS.

\section{Measurements}

The gait scale in the POMA was developed to evaluate the mobility and fall risk in the elderly [10]. The POMA consists of balance items ( 9 items, 16 points) and gait items ( 8 items, 12 points): 28 points in total. In this study, only the items for examining gait were used. The gait items consist of eight tasks such as gait initiation, step length in the left and right side, foot clearance, symmetrical gait, step continuity, path deviation, postural stability, and walking stance, and are examined on a 2-3-point scale: 12 points in total. In patients with stroke, the inter-rater reliability of the gait scale in the POMA was reported as intraclass correlation coefficient (ICC) $=0.85-94[21]$ and the test-retest reliability was ICC $=0.91[16]$.

Static balance was examined with the OLST. This tool is used to examine how long a patient can stand on one leg without external aids. The inter-rater reliability and intra-rater reliability was reported as ICC $=0.99$ [22]. Muscle strength of the lower extremity was examined with the SST. This tool is used to measure the time taken to repeat the sit to stand movement five times. The inter-rater reliability was reported as ICC $=0.97$ [23]. Gait ability was examined with the 10WT. This tool is aimed at having subjects walk independently $14 \mathrm{~m}$ at a comfortable standing posture without walk aids and measuring the time that they walked exclud- 
ing an acceleration area of 2-meter and deceleration area of 2-meter [24]. The test-retest reliability was reported as ICC $=0.88-0.97$ [25]. To examine the motor function in the affected side, the Fugl-Meyer assessment was used [26]. In this study, we used only the items for lower extremity, and the inter-rater reliability and intra-rater reliability were reported as $r=0.94$ and $r=0.99$, respectively [27]. To examine the trunk control ability, the TIS was used. The TIS consists of three items such as static sitting balance items that examine the ability to maintain a sitting posture with both feet on the ground and the lower extremity of the non-affected side crossed on that of the affected side ( 7 points), dynamic sitting balance items that examine the isolated movement of the upper trunk and lower trunk through the lateral flexion of the trunk (14 points), and coordination items that examine the rotation movement of the shoulder girdle and pelvic girdle on the horizontal surface (6 points). In stroke patients, the reliability was reported as $\mathrm{ICC}=0.96$ [28].

\section{Statistical analysis}

Statistical analysis was performed by using PASW ver. 18.0 (IBM Co., Armonk, NY, USA). Descriptive statistics were used to analyse the characteristics of the subjects. To identify the differences of the characteristics and physical functions between groups depending on falls, the chi-square test and independent t-test were performed. The cutoff value of the gait scale in the POMA on the prediction of falls using the receiver operating characteristic (ROC) curve was determined. The accuracy of prediction was measured by the area under the curve (AUC): $0.5<\mathrm{AUC} \leq 0.7$ was defined as less accuracy; $0.7<\mathrm{AUC} \leq 0.9$ as medium accuracy; 0.9 $<\mathrm{AUC}<1$ as high accuracy; and $\mathrm{AUC}=1$ as perfect accuracy [29]. When the cut-off value was significant, the independent $t$-test was conducted to determine if there was any difference in the physical functions (OLST, SST, 10WT, FM-LE, and TIS) depending on the cut-off value. To analyze the effect size in the two groups, Cohen d was used for verification [30]. Cohen $d$ is the value that normalized the average of the falls group compared to that of the non-falls group (average of the non-falls group - average of the falls group
/ total standard deviation). If $\mathrm{d} \geq 0.8$, the size effect is high, and if $d=0.6-0.8$, the size effect is moderate. In addition, to identify the influential factors in the gait scale of the POMA, the multiple linear regression analysis was used, and for the validity of falls prediction, the logistic regression analysis (forward-Wald) was used to obtain the odds ratio. The statistical significance level was set at $\alpha=0.05$.

\section{Results}

There was no difference in gender, age, diagnosis, affected side, and disease duration in the characteristics of subjects depending on the falls experience, but in the use of walk aids, there was a significant difference in the independent gait in 13 among 18 individuals in the non-falls group (72.22\%) and in 11 among 34 individuals in the falls group $(32.35 \%)$. In the comparison of physical functions, there was a significant difference in the Gait scale in POMA, OLST, SST, 10WT, FM-LE, and TIS between the falls group and the non-falls group (Table 1).

As a result of the ROC curve analysis, the cut-off value of the Gait scale in POMA for predicting falls was 8.5 (sensitivity $72 \%$; specificity $65 \%$ ) and the AUC was 0.75 (95\% confidence interval: $0.60-0.90, p<0.007$ ). Individuals with POMA gait scale scores of $\leq 8.5$ were more likely to fall than those with POMA gait scale scores of $>8.5$ (Table 2).

In the gait scale of the POMA, there was a significant difference in the OLST of the affected side, SST, FM-LE, and TIS between the group whose risk of falls was as low as $>8.5$ and the group whose risk of falls was $\leq 8.5$, but there was no significant difference in the OLST of the non-affected side and 10WT, and in the comparison of effect size, Cohen $\mathrm{d}=0.30-0.41$, which was rather low (Table 3 ).

For analysis of the factors affecting the Gait Scale in POMA, the SST had the highest impact ( $\beta=0.498$ ), followed by OLST of the affected side ( $\beta=0.223$ ), OLST of the non-affected side ( $\beta=0.219)$, and FM-LE ( $\beta=0.198)$ in order (adjust $\mathrm{R}^{2}=55 \%$ ) (Table 4 ).

As factors affecting the experience of falls, the subjects with POMA gait scale scores of $\leq 8.5$ were 1.240 times

Table 2. Cutoff value of the POMA-GS as the factor for predicting falls

\begin{tabular}{cccccc}
\hline Type & Cut-off value & Sensitivity (\%) & Specificity (\%) & ROC curve (95\% CI) & $p$ \\
\hline Non-fallers vs. fallers & $\leq 8.5$ score & 72 & 65 & $0.75(0.60-0.90)$ & $0.007^{*}$ \\
\hline
\end{tabular}

POMA-GS: Performance-Oriented Mobility Assessment-Gait Scale, ROC: receiver operating characteristic, CI: confidential interval. Significant differences among three groups were presented as ${ }^{*} p<0.01$. 
Table 3. Comparison of the physical functions depending on the cut off value of the POMA-GS

\begin{tabular}{|c|c|c|c|c|c|}
\hline \multirow{2}{*}{ Variable } & \multicolumn{2}{|c|}{ Type } & \multirow{2}{*}{$\mathrm{t}$} & \multirow{2}{*}{$p$} & \multirow{2}{*}{ Cohen d } \\
\hline & POMA-GS ( $\leq 8.5$ score $)$ & POMA-GS (>8.5 score) & & & \\
\hline OLST of affected side (s) & $1.85(1.44)$ & $4.42(3.85)$ & 3.236 & $0.002^{* *}$ & 0.82 \\
\hline OLST of non-affected side & $7.36(4.87)$ & $9.30(7.67)$ & 1.095 & 0.279 & 0.30 \\
\hline $10 \mathrm{WT}(\mathrm{m} / \mathrm{s})$ & $0.65(0.34)$ & $0.79(0.34)$ & 1.503 & 0.139 & 0.41 \\
\hline $\mathrm{SST}(\mathrm{s})$ & $18.62(7.36)$ & $14.06(6.70)$ & -2.332 & $0.024^{*}$ & 0.62 \\
\hline FM-LE (score) & $20.07(6.73)$ & $24.36(7.19)$ & 2.221 & $0.031^{*}$ & 0.59 \\
\hline TIS (score) & $14.48(4.55)$ & $19.48(3.10)$ & 4.592 & $0.001^{* * *}$ & 1.08 \\
\hline
\end{tabular}

The values are presented as mean (SD).

POMA-GS: Performance-Oriented Mobility Assessment-Gait Scale, OLST: One Leg Stand Test, 10WT: 10-m Walk Test, SST: Sit to Stand Test, FM-LE: Lower Extremity in Fugl-Myer assessment, TIS: Trunk Impairment Scale.

Significant differences among three groups were presented as ${ }^{*} p<0.05,{ }^{* *} p<0.01,{ }^{* * *} p<0.001$.

Table 4. Analysis of factors affecting POMA-GS

\begin{tabular}{|c|c|c|c|c|c|c|c|}
\hline Independent variable & Regression coefficient & Standard error & $\beta$ & $\mathrm{t}$ & $p$ & $\operatorname{adj} R^{2}$ & $\mathrm{~F}$ \\
\hline Constant & 5.686 & 0.792 & & 7.178 & $0.001^{* * *}$ & \multirow{5}{*}{0.55} & \multirow{5}{*}{$16.513^{* * *}$} \\
\hline SST & 0.592 & 0.119 & 0.498 & 4.951 & $0.001^{* * *}$ & & \\
\hline OLST of affected side & 0.813 & 0.384 & 0.223 & 2.119 & $0.039^{*}$ & & \\
\hline OLST of non-affected side & 0.469 & 0.225 & 0.219 & 2.086 & $0.042^{*}$ & & \\
\hline FM-LE & 0.047 & 0.023 & 0.198 & 2.042 & $0.047^{*}$ & & \\
\hline
\end{tabular}

Independent variables: Gender, age, etiology, affected side, walking aids, stroke duration, number of fall, OLST of affected side, OLST of non-affected side, SST, 10-m Walk Test, FM-LE, Trunk Impairment Scale. Dependent variable: POMA-GS.

POMA-GS: Performance-Oriented Mobility Assessment-Gait Scale, SST: Sit to Stand Test, OLST: One Leg Stand Test, FM-LE: Lower Extremity in Fugl-Myer assessment.

Significant differences among three groups were presented as ${ }^{*} p<0.05,{ }^{* * *} p<0.001$.

Table 5. Analysis of factors in the experience of falls

\begin{tabular}{ccccccc}
\hline Independent variable & Dependent variable & Regression coefficient & Standard error & Wald & $p$ & Odd ratio (95\% CI) \\
\hline POMA-GS & Fall & 0.215 & 0.071 & 9.289 & $0.002^{* *}$ & $1.240(1.080-1.424)$ \\
SST & & -0.195 & 0.097 & 4.044 & $0.044^{*}$ & $0.823(0.681-0.995)$ \\
\hline
\end{tabular}

Independent variables: Gender, age, etiology, affected side, walking aids, stroke duration, number of fall, One Leg Stand Test of affected side, OLST of non-affected side, SST, 10-m Walk Test, Lower Extremity in Fugl-Myer assessment, Trunk Impairment Scale, POMA-GS $(\leq 8.5$ score $=0,>8.5$ score $=1)$ Dependent variable: fall (non-fall $=0$, fall $=1$ ).

CI: confidence interval, POMA-GS: Performance-Oriented Mobility Assessment-Gait Scale, SST: Sit to Stand Test.

Significant differences among three groups were presented as ${ }^{*} p<0.05,{ }^{* *} p<0.01$.

more likely to be at risk of falls than subjects with Gait scale in POMA gait scale scores of $>8.5$, and the subjects who took less time to perform the SST were 0.823 times more likely to be at risk of falls than those who took more time to perform the SST (Table 5).

\section{Discussion}

In the clinical setting, it is very important to evaluate the gait ability of stroke patients and related falls, and many study findings on the examination tools have been reported [31]. In this study, the cut-off value of the gait scale of the POMA that predicted falls was 8.5 (12 points in total). Such an attempt was made for the first time and could not be compared with the previous studies, but in this study, the AUC of the Gait scale in POMA was 0.75 and had medium accuracy [29]. Thus, the Gait scale in POMA had discrimination capability that could predict falls in patients with chronic stroke. In addition, to identify the sufficient validity of the gait scale in POMA in evaluating gait patterns, the cut-off value of the 
gait scale that could predict falls was used to understand the difference. As a result, subjects with POMA gait scale scores of $>8.5$ were excellent at functional ability (the OLST of affected side, SST, FM-LE, and TIS) compared with subjects with POMA gait scale scores $\leq 8.5$. In general, stroke patients have impaired postural stability [32] and thus rely more heavily on the lower extremity of the non-affected side to maintain balance, and the asymmetrical weight bearing becomes severe [33,34]. In addition, as stroke patients rely more heavily on vision than proprioceptor when performing the OLST [35], postural sway appears more significant and it also has a negative impact on postural control. As it relies more heavily on the lower extremity of the non-affected side, postural sway velocity increases and asymmetrical weight bearing appears and negatively impacts stability in standing. As shown in the gait scale of POMA, step continuity, hesitation when starting to walk, step length in the left and right side, foot clearance, body sway, and walking stance are influenced by the ability to adjust the lower extremity of the affected side in stroke patients. When compared between subjects with POMA gait scale scores of $>8.5$ and $\leq 8.5$, the $10 \mathrm{WT}$ was $0.79 \mathrm{~m} / \mathrm{s}$ and $0.65 \mathrm{~m} / \mathrm{s}$, respectively. All subjects were classified into the limited community gait group [36], but the subjects with POMA gait scale scores of $>8.5$ scored $2.84(\mathrm{~km} / \mathrm{h})$ on the 10WT and the subjects with POMA gait scale scores of $\leq 8.5$ scored $2.34(\mathrm{~km} / \mathrm{h})$ on the 10WT. Thus, their physical activity levels appeared to be 2.48 Metabolic Equivalent Task (MET) and 2.04 MET, respectively [37]. In general, a gentle stroll in the garden was $2.3 \mathrm{MET}$ and an activity of daily living such as meal preparation or house cleaning was 2.5 MET according to the standard figures of healthy adults. Given these standards, the subjects with POMA gait scale scores of $\leq 8.5$ were included in the limited community gait group and could not participate in a gentle stroll in the garden. As they have many restrictions in physical activities, these individuals are more likely to be exposed to the risk of falls. In addition, if the gait speed of stroke patients is less than 0.56 $\mathrm{m} / \mathrm{s}$ ), the risk of repeated falls is higher. Thus, the stroke patients with POMA gait scale scores of $\leq 8.5$ (gait speed 0.65 $\mathrm{m} / \mathrm{s}$ ) are likely to be at risk of falls. Given that the cut-off value of the SST for predicting falls in stroke patients was reported at 17.9 seconds [38], the subjects with POMA gait scale scores of $\leq 8.5$ to predict the risk of falls are likely to be at risk of falls. According to Yates et al. [39], the lower the motor function of the lower extremity in the affected side, the higher the probability of experiencing falls, and if the
$\mathrm{FM}$ is $\leq 28$, the probability of falls increases by 2.2 times. If the FM $<23.8$, the risk of falls increases by one time [40]. The present study is also consistent with the approximate values that the subjects with POMA gait scale scores of $\leq 8.5$ are likely to experience falls one time, because its score was 20.07. Moreover, regarding the relevance of falls incidence and posture control in stroke patients, there was a significant relationship between increased body sway and number of falls $(r=0.27)$, and increased body sway can influence $10 \%$ of falls [41]. Impaired postural control is a fall risk factor in stroke patients [42]. In addition, if the TIS is $<20$, postural control is impaired and independent activity of daily life is impossible [43]. In this study, the TIS of the subjects with POMA gait scale scores of $>8.5$ and $\leq 8.5$ were 19.48 and 14.48 , respectively, which was not comparable to the standards in the previous studies, but the functional independent level of the subjects with POMA gait scale scores of $\leq 8.5$ was significantly low.

Taken together, the cut-off value of the POMA gait scale scores of that predicts falls can be used as an examination tool to predict falls in stroke patients because it is sufficiently valid in identifying the relationship with dynamic balance, muscle strength of lower extremity, gait speed, motor function in the affected side, and trunk control. However, the POMA gait scale scores of is aimed at examining quick gait speed through visual observation at fixed sections, unlike the gait examination tools with specific tasks (dual cognitive task), and thus affected by gait speed. Thus, it is an inappropriate tool for patients with quick gait speed because of the ceiling effect. However, it has an advantage in that it is easy to identify asymmetrical gait patterns in patients who use walk aids or whose gait speed is slow; thus, it may be useful for identifying the relevance with falls. Gait variability is significantly related to impaired balance and increased risk of falls [44]. In this study, the factors that greatly affect the gait scale of the POMA are the SST (muscle strength of lower extremity), OLST of the affected side (weight bearing to the affected side), OLST of the non-affected side (weight bearing to the non-affected side), and FM (motor function of the lower extremity in the affected side). This result can be explained by the characteristics of the examination items in the gait scale of the POMA. For normal gait through coordinated movement of the lower extremity based on the normal gait cycle, muscle strength of the lower extremity, symmetrical weight bearing, and motor control of the affected side are necessary. In addition, the gait scale of the POMA consists of gait examination items 
for coordinated movement with spatial parameter of gait like stride length that may influence the gait speed [15]. To perform the SST, the ability to adjust the center of mass at the base of support, symmetrical weight bearing of the two lower extremities, and strength of the lower extremity are required [45]. Postural stability for gait requires sufficient stability in the stance phase in both lower extremities and appropriate relocation of the foot for weight acceptance and the lower extremities corresponding to the swing phase, and it can be examined by the OLST. Furthermore, motor control of the lower extremity in the affected side is a prerequisite for coordinative gait (symmetry, step continuity) by adjusting the isolated movement of each joint of the lower extremity.

As analysis of factors affecting the experience of falls, the subjects with total scores of $\leq 8.5$ were 1.24 times more likely to be at risk of falls (odds ratio), and subjects who took less time to perform the SST were 0.823 times more likely to be at risk of falls than those who took more time to perform the SST. Stroke patients who had significantly reduced motor function of the affected side and low gait speed showed frequent preliminary movements that might cause falls during gait, such as hesitation when starting to walk, foot clearance [12,20], unstable postural sway [41], and step discontinuity like walking stance [20], and they were more likely to be at risk of falls. Such a phenomenon can be observed in the examination with the gait scale of the POMA. Taken together, the gait scale of the POMA is expected to be a very useful examination tool in clinical settings because it has satisfactory discrimination capacity and predictive validity to predict the risk of falls in survivors with chronic stroke.

However, a few limitations exist in this study. There may be cases deviating from the definition of falls since records for whether a fall occurred were based on the subjects' recollection. In addition, the POMA-GS was measured at a particular point in time. Therefore, the results may have limited applicability to all stroke survivors. Thus, a prospective study including numerous important factors on whether the gait scale of the POMA can predict falls for stroke patients should be performed in the future.

\section{Conflict of Interest}

The authors declared no potential conflicts of interest with respect to the authorship and/or publication of this article.

\section{References}

1. Capaday C. The special nature of human walking and its neural control. Trends Neurosci 2002;25:370-6.

2. Urban PP, Wolf T, Uebele M, Marx JJ, Vogt T, Stoeter P, et al. Occurence and clinical predictors of spasticity after ischemic stroke. Stroke 2010;41:2016-20.

3. Patterson KK, Parafianowicz I, Danells CJ, Closson V, Verrier MC, Staines WR, et al. Gait asymmetry in community-ambulating stroke survivors. Arch Phys Med Rehabil 2008;89:304-10.

4. Patterson SL, Forrester LW, Rodgers MM, Ryan AS, Ivey FM, Sorkin JD, et al. Determinants of walking function after stroke: differences by deficit severity. Arch Phys Med Rehabil 2007;88: 115-9.

5. Tyson SF, Hanley M, Chillala J, Selley A, Tallis RC. Balance disability after stroke. Phys Ther 2006;86:30-8.

6. Harada N, Chiu V, Damron-Rodriguez J, Fowler E, Siu A, Reuben DB. Screening for balance and mobility impairment in elderly individuals living in residential care facilities. Phys Ther 1995;75:462-9.

7. de Oliveira CB, de Medeiros IR, Frota NA, Greters ME, Conforto AB. Balance control in hemiparetic stroke patients: main tools for evaluation. J Rehabil Res Dev 2008;45:1215-26.

8. Shumway-Cook A, Gruber W, Baldwin M, Liao S. The effect of multidimensional exercises on balance, mobility, and fall risk in community-dwelling older adults. Phys Ther 1997;77:46-57.

9. Wrisley DM, Walker ML, Echternach JL, Strasnick B. Reliability of the dynamic gait index in people with vestibular disorders. Arch Phys Med Rehabil 2003;84:1528-33.

10. Tinetti ME. Performance-oriented assessment of mobility problems in elderly patients. J Am Geriatr Soc 1986;34:119-26.

11. Jacobs JV, Horak FB, Tran VK, Nutt JG. Multiple balance tests improve the assessment of postural stability in subjects with Parkinson's disease. J Neurol Neurosurg Psychiatry 2006;77: 322-6.

12. Maki BE, McIlroy WE. Control of rapid limb movements for balance recovery: age-related changes and implications for fall prevention. Age Ageing 2006;35 Suppl 2:ii12-8.

13. Sackley $\mathrm{C}$. The relationship between weight-bearing asymmetry after stroke, motor function and activities of daily living. Physiother Theory Pract 1990;6:179-85.

14. Bloem BR, Grimbergen YA, Cramer M, Willemsen M, Zwinderman AH. Prospective assessment of falls in Parkinson's disease. J Neurol 2001;248:950-8.

15. Canbek J, Fulk G, Nof L, Echternach J. Test-retest reliability and construct validity of the tinetti performance-oriented mobility assessment in people with stroke. J Neurol Phys Ther 2013;37: 14-9.

16. Daly JJ, Roenigk K, Holcomb J, Rogers JM, Butler K, Gansen J, et al. A randomized controlled trial of functional neuromuscular stimulation in chronic stroke subjects. Stroke 2006;37:172-8.

17. Corriveau H, Hébert R, Raîche M, Prince F. Evaluation of postural stability in the elderly with stroke. Arch Phys Med Rehabil 2004;85:1095-101.

18. Soyuer F, Oztürk A. The effect of spasticity, sense and walking aids in falls of people after chronic stroke. Disabil Rehabil 2007;29:679-87. 
19. Thomas JI, Lane JV. A pilot study to explore the predictive validity of 4 measures of falls risk in frail elderly patients. Arch Phys Med Rehabil 2005;86:1636-40.

20. Lamb SE, Jørstad-Stein EC, Hauer K, Becker C; Prevention of Falls Network Europe and Outcomes Consensus Group. Development of a common outcome data set for fall injury prevention trials: the Prevention of Falls Network Europe consensus. J Am Geriatr Soc 2005;53:1618-22.

21. Sterke CS, Huisman SL, van Beeck EF, Looman CW, van der Cammen TJ. Is the Tinetti Performance Oriented Mobility Assessment (POMA) a feasible and valid predictor of short-term fall risk in nursing home residents with dementia? Int Psychogeriatr 2010;22:254-63.

22. Franchignoni F, Tesio L, Martino MT, Ricupero C. Reliability of four simple, quantitative tests of balance and mobility in healthy elderly females. Aging (Milano) 1998;10:26-31.

23. Mong Y, Teo TW, Ng SS. 5-repetition sit-to-stand test in subjects with chronic stroke: reliability and validity. Arch Phys Med Rehabil 2010;91:407-13.

24. Ng SS, Ng PC, Lee CY, Ng ES, Tong MH. Walkway lengths for measuring walking speed in stroke rehabilitation. J Rehabil Med 2012;44:43-6.

25. Flansbjer UB, Holmbäck AM, Downham D, Patten C, Lexell J. Reliability of gait performance tests in men and women with hemiparesis after stroke. J Rehabil Med 2005;37:75-82.

26. Fugl-Meyer AR, Jääskö L, Leyman I, Olsson S, Steglind S. The post-stroke hemiplegic patient. 1. A method for evaluation of physical performance. Scand J Rehabil Med 1975;7:13-31.

27. Duncan PW, Propst M, Nelson SG. Reliability of the Fugl-Meyer assessment of sensorimotor recovery following cerebrovascular accident. Phys Ther 1983;63:1606-10.

28. Verheyden G, Nieuwboer A, Mertin J, Preger R, Kiekens C, De Weerdt W. The Trunk Impairment Scale: a new tool to measure motor impairment of the trunk after stroke. Clin Rehabil 2004; 18:326-34.

29. Greiner M, Pfeiffer D, Smith RD. Principles and practical application of the receiver-operating characteristic analysis for diagnostic tests. Prev Vet Med 2000;45:23-41.

30. Nakagawa S. A farewell to Bonferroni: the problems of low statistical power and publication bias. Behavi Ecol 2004;15:1044-5.

31. Cho KH, Lee WH. Changes of spatio-temporal gait parameters according to experience falls in post-stroke patients. Phys Ther Rehabil Sci 2012;1:22-7.

32. Park KS, Choi JD. The effect of balance training with plantar flexor stretching on range of motion, balance, and gait in stroke patients: a randomized controlled pilot trial. Phys Ther Rehabil
Sci 2015;4:66-72.

33. Cho J, Lee E, Lee S. Effects of body weight-supported treadmill training combined with ball-kicking on balance and gait of subacute stroke patients. Phys Ther Rehabil Sci 2015;4:73-8.

34. Shin J, Chung Y. The effect of treadmill gait training with patellar taping on gait abilities in chronic stroke patients. Phys Ther Rehabil Sci 2015;4:94-102.

35. Bonan IV, Yelnik AP, Colle FM, Michaud C, Normand E, Panigot B, et al. Reliance on visual information after stroke. Part II: Effectiveness of a balance rehabilitation program with visual cue deprivation after stroke: a randomized controlled trial. Arch Phys Med Rehabil 2004;85:274-8.

36. Taylor D, Stretton CM, Mudge S, Garrett N. Does clinic-measured gait speed differ from gait speed measured in the community in people with stroke? Clin Rehabil 20061;20:438-44.

37. Ainsworth BE, Haskell WL, Whitt MC, Irwin ML, Swartz AM, Strath SJ, et al. Compendium of physical activities: an update of activity codes and MET intensities. Med Sci Sports Exerc 2000;32:S498-504

38. Beninato M, Portney LG, Sullivan PE. Using the International Classification of Functioning, Disability and Health as a framework to examine the association between falls and clinical assessment tools in people with stroke. Phys Ther 2009;89:816-25.

39. Yates JS, Lai SM, Duncan PW, Studenski S. Falls in community-dwelling stroke survivors: an accumulated impairments model. J Rehabil Res Dev 2002;39:385-94.

40. Belgen B, Beninato M, Sullivan PE, Narielwalla K. The association of balance capacity and falls self-efficacy with history of falling in community-dwelling people with chronic stroke. Arch Phys Med Rehabil 2006;87:554-61.

41. Sackley CM. Falls, sway, and symmetry of weight-bearing after stroke. Int Disabil Stud 1991;13:1-4.

42. Andersson AG, Kamwendo K, Seiger A, Appelros P. How to identify potential fallers in a stroke unit: validity indexes of 4 test methods. J Rehabil Med 2006;38:186-91.

43. Verheyden G, Nieuwboer A, Feys H, Thijs V, Vaes K, De Weerdt W. Discriminant ability of the trunk impairment scale: a comparison between stroke patients and healthy individuals. Disabil Rehabil 2005;27:1023-8.

44. Verma R, Arya KN, Sharma P, Garg RK. Understanding gait control in post-stroke: implications for management. J Bodyw Mov Ther 2012;16:14-21.

45. Cheng PT, Chen CL, Wang CM, Hong WH. Leg muscle activation patterns of sit-to-stand movement in stroke patients. Am J Phys Med Rehabil 2004;83:10-6. 